\title{
Preface: History of regional warning centers
}

\author{
Phil Wilkinson ${ }^{1, *}$ \\ ${ }^{1}$ IPS, Bureau of Meteorology, Sydney, Australia \\ * retired \\ Correspondence: Phil Wilkinson (phil_wilkinson@internode.on.net)
}

Published: 12 March 2018

The influence of the Sun on the Earth is well known, but the extent to which the solar influence permeates the space environment from the solar surface out to the heliopause, beyond the orbit of Pluto, and in particular its effect on terrestrial technological systems, is less familiar. Prior to 1940 research identified some of the many ways solar disturbances could affect, for instance, high-frequency communications. During World War 2, this problem was of practical importance, and solutions, plus the lack of solutions, were highly classified. At the end of the war, sufficient skill had been developed that some countries found it worthwhile to continue to provide forecasts, tailored to their local needs, to mitigate the solar influence on high-frequency communications and to a lesser extent on magnetic observations. There was limited to no exchange of observations and forecasts between national agencies other than the URSIgram (e.g., Davis, 1935) for those who could receive the Morse code transmissions.

The proposal that led to the development of the International Geophysical Year (IGY) needed solar forecasting services to carry out a more efficient scientific programme. This led to the development of the concept of a Regional Warning Centre (RWC) and Associate RWC (ARWC). To facilitate the exchange of data between agencies a set of agreed codes were endorsed and were refined throughout the IGY period and subsequently. The RWC and ARWC used local and exchanged data to make forecasts for the forthcoming day, and they were exchanged and the final forecast compiled from these at the US RWC, called the World Warning Agency (WWA), at Fort Belvoir, Virginia, USA. These and other activities formalized during the IGY are outlined in Shapley (1959).

Following the IGY the RWCs were grouped together with a common purpose under the auspices of the International URSIgram and World Day Services (IUWDS) (Simon, 1981).

The term "space weather" came into common usage somewhere between 1990 and 1995. It was the common term that recognized the pervasive impact of the Sun and the space environment on man's activities. To align IUWDS better with the growing field of space weather, in 1996 it was renamed the International Space Environment Services (ISES), which more accurately described its functions. Poppe and Jordan (2006) provide a general summary of these early developments, focusing especially on the US developments.

The people responsible for staffing the RWCs prior to and immediately after the IGY have now all retired, and many, possibly most, are dead. In fact, in many cases their successors have also retired. Each RWC will have evolved in a different way: some may have recorded their history already, and others will possibly find it hard to develop a clear vision of these early beginnings. In other cases, countries recognizing the importance of ISES have developed their RWCs more recently. Finally, recognizing the importance of space weather services, all the current RWCs are working to cooperate with the World Meteorological Organization to enhance the global recognition and distribution of space disturbance warnings.

This special issue will collect together papers that describe the evolution of the RWCs that make up ISES, in some cases from their beginnings prior to IGY, through to nearer the present day.

\section{References}

Davis, W.: Cosmic-data URSIgrams, in: Reports and Papers, General Assembly, 1935, 41-49, https://doi.org/10.1029/TR016i001p00041, 1935.

Poppe, B. E. and Jordan, K. P.: Sentinels of the Sun: Forecasting Space Weather, Johnson Books, Boulder, CO, 196 pp., 2006.

Shapley, A. H.: The Day-to-Day Coordination of IGY Observations, P. IRE, 47, 323-327, https://doi.org/10.1109/JRPROC.1959.287301, 1959.

Simon, P. A.: The International URSIGRAM and World Days Service, in: Automated data retrieval in astronomy, edited by: Jaschek, C. and Heintz, W., D. Reidel Publishing Company, 7375,1981 . 